\title{
The Effect of the Change in the Position of Load on the Inclination Angle of Floating Crane
}

\author{
Tran Van Tao, Nguyen Chien Luy \\ Faculty of Transportation Engineering, Ho Chi Minh City University of Technology, Ho Chi Minh City, Vietnam \\ Email address: \\ tao.tranvan@hcmut.edu.vn (T. V. Tao), nguyenchienluy3009@gmail.com (N. C. Luy)
}

\section{To cite this article:}

Tran Van Tao, Nguyen Chien Luy. The Effect of the Change in the Position of Load on the Inclination Angle of Floating Crane. International Journal of Transportation Engineering and Technology. Special Issue: Transportation Engineering Technology and Education.

Vol. 6, No. 4, 2020, pp. 118-122. doi: 10.11648/j.ijtet.20200604.12

Received: November 6, 2020; Accepted: December 5, 2020; Published: December 11, 2020

\begin{abstract}
Floating cranes are equipment used for the transport of goods in the ports of Viet Nam. Some of the floating cranes such as the equipment to renovate river cages are also widely used in Vietnam. During operation, the balance of the floating cranes differs from that of the land cranes because of changes in the volume displacement. Besides, the center of the entire structure will vary depending on the location of the goods. For floating cranes the research document is often interested in statically and dynamically stabilizing. Static stability in idle or under load condition is no longer considered by checking whether the stabilization moment is greater than the overturning moment. The dynamic stability was the static balance of the crane is disturbed and behave like certain periodic or unexpected movements on the way to a different balancing position. However, this article refers to the effect of the lifting process on the static equilibrium of floating cranes. The stability of the floating crane is differ from normal ship especially when it is lifting cargo or goods, when the hangging cargo changes its position that will effect to the position of the gavity center of the total weight. In this paper we would like to show the way to calculate hydrostatic and stability of floating crane, especially the changing of inclination angle (heeling and pitching angle) as the hangging goods change its position.
\end{abstract}

Keywords: Floating Crane Operation, Crane Hydrostatic Stability, Floating Crane Stability, Floating Crane Dynamics

\section{Introduction}

The demand for marine and island environment, resources is increasing to meet the needs of the country's economic development. Offshore works are constructed such as oil and gas fields, pontoon bridge... So the attention to safety and performance of these works at operation is necessary. Unlike on land, with marine buildings the main threat is the influence of the surrounding environment such as wind, waves, corrosion, changes of the sea.

Floating cranes are equipped which carries goods from one place to another, often used in the construction or repair of offshore installations. A load suspended on a crane fastened to the hull can be easily affected by waves, wind, ocean currents $[1,2]$. This will create complex, uncontrollable non-linear motions that cause accidents. In fact, many cranes-related jobs were postponed due to bad sea conditions, which prolonged the time and increased the cost of the project. Therefore, studies on floating cranes aim to carry out offshore activities more efficiently, safely and reduce costs.

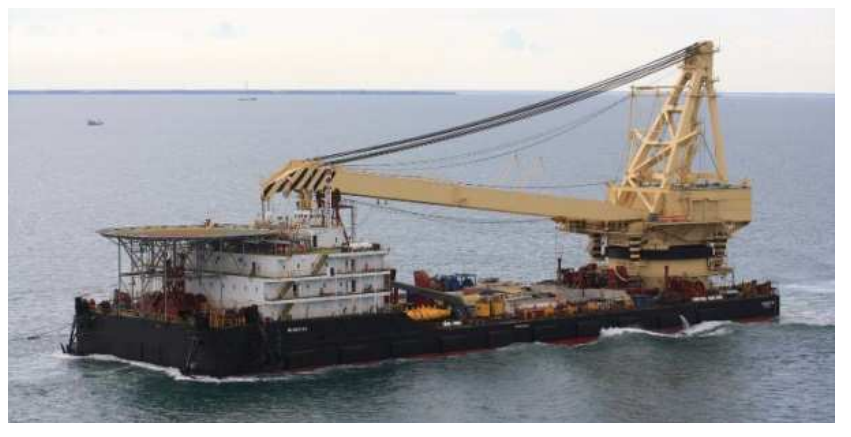

Source: https://www.marinetraffic.com

Figure 1. Floating crane (Hoang Sa).

Kind of floating crane often used in Vietnam is the same to figure 1 . We would like to use this crane to calculate in this paper. During operation, changing the position of goods will easily change the position of the whole system of floating cranes (figure 2). This change affects the balance of floating cranes. Static stability and dynamic stability are two states that 
are often considered, when a system is imbalanced on the water surface. Static stabilization is considering the recovery torque value that appears when tilting the vessel. The torque recovers against the tilted torque, and when the inclined torque no longer acts, the restored torque returns the ship to a balanced position. Dynamic balance appears when the static balance is affected by external forces that lead the system to a new balanced position.

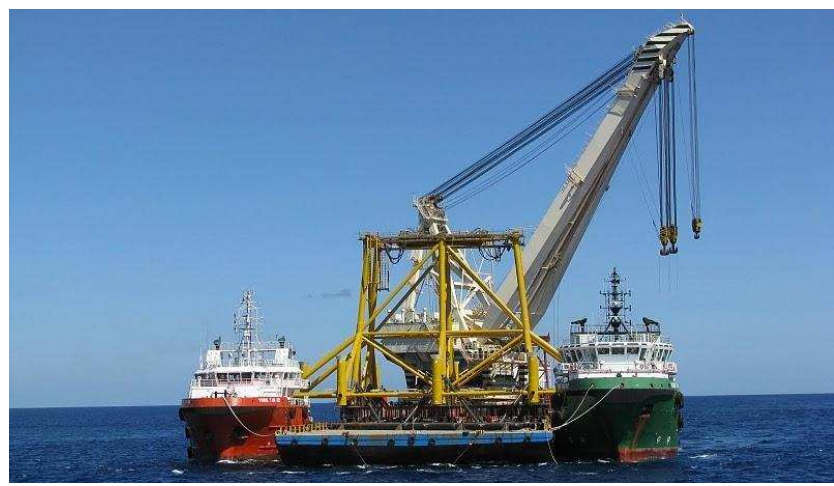

Source: https://www.marinetraffic.com

Figure 2. Floating crane operation.

This paper focuses research on the static balance of floating cranes. During operation, the position of goods changes the center of the system. The change of the center will affect the tilt angle of the floating crane. The paper will make assumptions about changing the position of goods affecting the angle of inclination of floating cranes and find out the connection between them.

\section{Hydrostatic and Stability of Floating Crane}

In this paper, the floating crane is modelling as is a system consisting of a pontoon carring a crane, figure 3 .

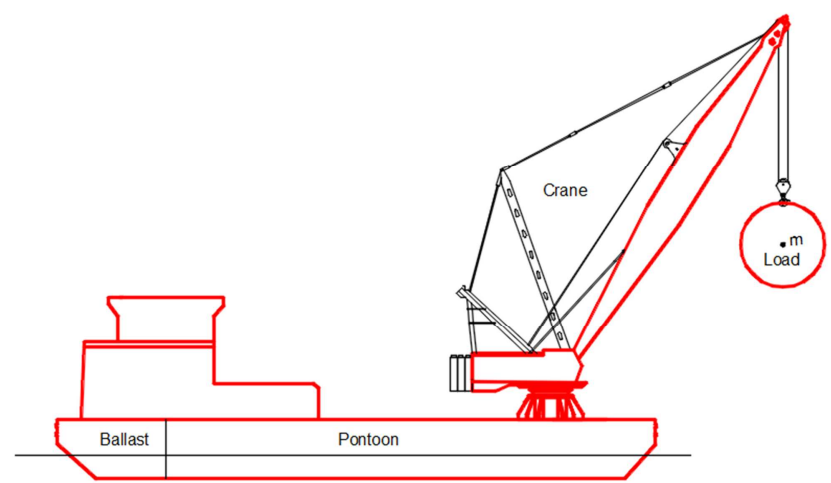

Figure 3. Floating crane modeling.

During the process of lifting, load is lifting from curent position $\left(x_{1}, z_{1}\right)$ to the next position $\left(x_{2}, z_{2}\right)$ (Figure 4$)$. When the load reach to new position, the center $G$ of the whole floating crane will changes. This lead to the changing of metacentric height GM, and make incline angle. In oder to keep the stability, the floating crane have to make a force or momentum which belong to value of stability lever $\mathrm{L}_{\mathrm{k}}$.

In this paper, we want to study about the changing of incline angle when the load is lifting and hope this result can be used in the study of dynamic in future.
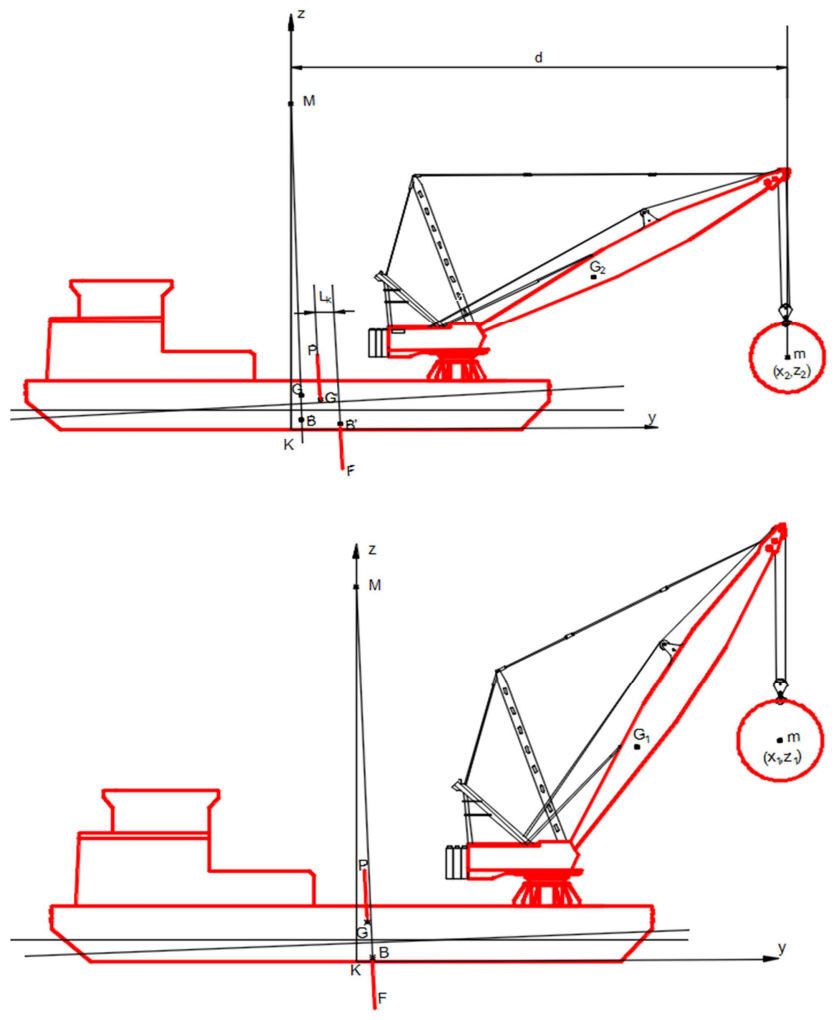

Figure 4. Cargo lifting process.

In figure 5, we assume that gravity force $\mathrm{P}$ (or total weight of the floating crane) and buoyancy force $\mathrm{F}$ are putting at the center $\mathrm{G}$ and $\mathrm{B}$.

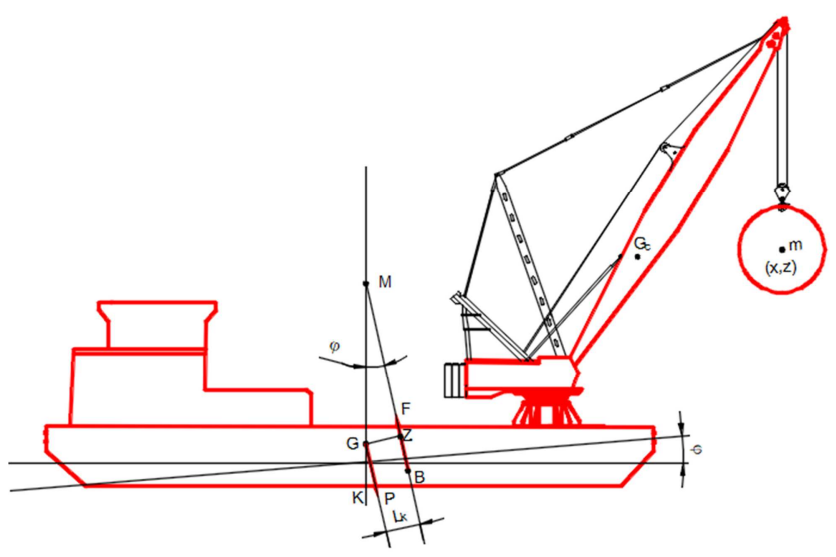

Figure 5. Cargo lifting process.

When the total weight $\mathrm{P}$ is greater than $\mathrm{F}$, the vessel will be pulled down. As the sinking deeper in the water the volume of the sinking part of the ship increased, according to Archimedes law the force $\mathrm{F}$ grew. When crossing the balance limit, F > P the situation will look back. The ship is balanced 
only when located in a position of 2 equal forces.

$$
F=P
$$

However, when the condition (1) have not ensured that the ship is stable. In case the vessel is tilted, the position of the center of buoyancy changes, the floating force line through the center B' does not coincide with the gravity effect line through $\mathrm{G}^{\prime}$ (figure 5). In this tilted state caused by heeling moment $M_{h}$ besides the distance between the two forces-acting lines carries a certain value of $\mathrm{Lk}$, righting moment appears $M_{r}=F \times G Z$. As the ship continued to tilt, the angle of inclination $\varphi$ changed, increasing. The state of balance is determined when [3]:

$$
M_{h}=M_{r}
$$

Which we have: $F=P$, so:

$$
G Z=\frac{M_{h}}{P}
$$

And incline angle can be [4]:

$$
\sin \varphi=\frac{G Z}{G M}
$$

In some case, to calculate longitudinal metacentric height:

$$
G M_{L}=\frac{I_{L}}{V}
$$

We have longitudinal moment of inertia of waterplane [5]:

$$
I_{L}=\int_{L} x^{2} y d x
$$
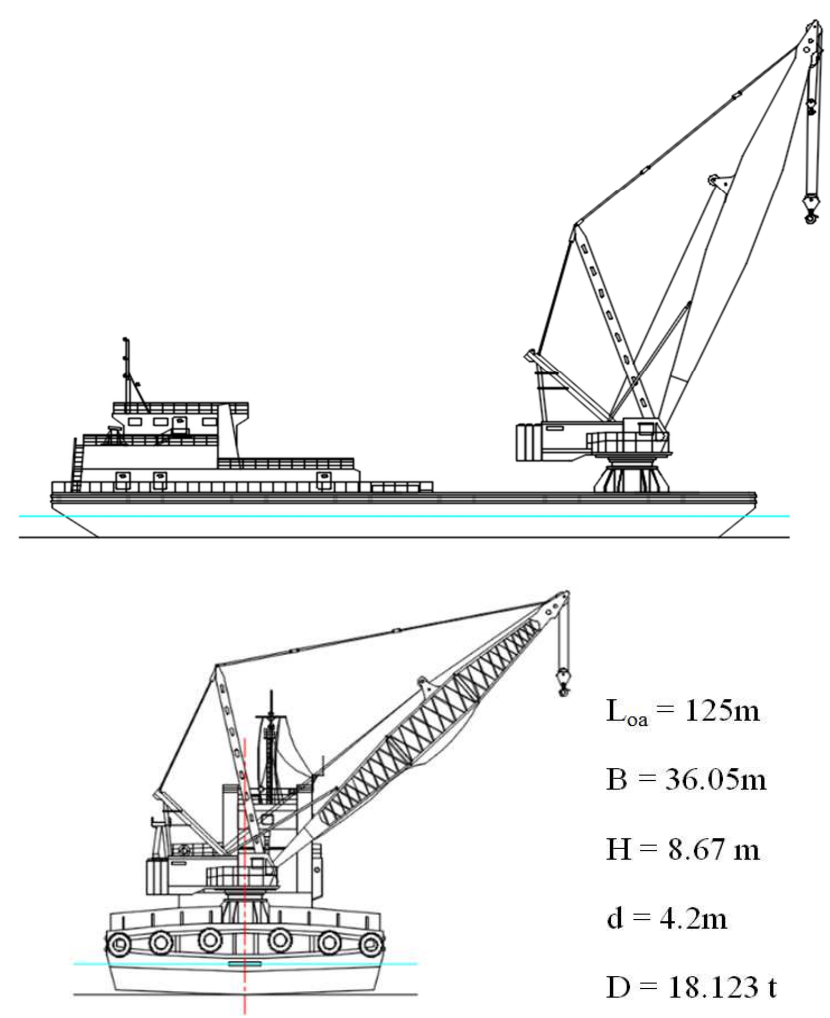

Figure 6. Hoang Sa Floating crane.

\section{Case Study}

\subsection{Basic Parameter of the Model-Floating Crane}

Crane Barge Hoang Sa $[6,7]$ is currently located at SEASIA South-East Asia at position $10^{\circ} 23^{\prime} 18.384^{\prime \prime} \mathrm{N}, 107^{\circ} 5^{\prime} 28.32^{\prime \prime}$ $\mathrm{E}$ as reported by Marine Traffic Terrestrial Automatic Identification System on 2020-11-16 05: 34 UTC. The wind in this area at that time blows from Northeast direction at force 4 Beaufort. Hoang Sa (IMO: 8757233) is a Crane Barge that is sailing under the flag of Vietnam. It's carrying capacity is 12993 DWT and her current draught is reported to be 4.2 meters. Her length overall (LOA) is 125 meters and her width is 36.05 meters (figure 6).

\subsection{Result of Hydrotasic and Stability of Floating Crane [8-10]}

Displacement volume:

$$
V=L \times B \times D \times C_{b}=18927 \mathrm{~m}^{3}
$$

According to the ship's image, we have longitudinal moment of inertia of waterplane:

$$
I_{L}=\int_{L} x^{2} y d x=5870000 m^{4}
$$

We have longitudinal metacentric height:

$$
G M_{L}=\frac{I_{L}}{V}=310 \mathrm{~m}
$$

And: $L k=G Z=\frac{M_{h}}{P}=\frac{m \times d}{\gamma \times V}=\frac{m \times d}{19400}$

With $\sin \varphi=\frac{G Z}{G M}$, we have a formula according to parameters $\mathrm{m}$ and $\mathrm{d}$ :

$$
\sin \varphi=\frac{m \times d}{19400 * 310}=\frac{m \times d}{6014000}
$$

Buoyancy center above moulded base:

$$
K B=\frac{\int_{0}^{z} A w(z) \times z d z}{V}=\frac{39745}{18926}=2.1 \mathrm{~m}
$$

Metacenter above center of buoyancy:

$$
B M=\frac{I_{T}}{V}=\frac{488030}{18926}=25.8 \mathrm{~m}
$$

Center of gravity above moulded base:

$$
K G=\frac{\sum w_{i} z_{i}}{\sum w_{i}}=3.9 \mathrm{~m}
$$

Metacentric height:

$$
G M=K B+B M-K G=24 m
$$

With $\sin \varphi=\frac{G Z}{G M}$, we have a formula according to parameters $\mathrm{m}$ and $\mathrm{d}$ : 


$$
\sin \varphi=\frac{m \times d}{19400 * 24}=\frac{m \times d}{465600}
$$

The result in table 1 and table 2 show the calculating of heeling and pitching angle when load change its position.

Base on the the result in tables 1 and 2, figures 7 and 8 show that when the load change position heeling and pitching angle change linearly. This is normal because the floating (pontoon) has box shape.

Table 1. Pitching angle when changing the position of load.

\begin{tabular}{lll}
\hline $\mathbf{m}$ & $\mathbf{d}$ & $\boldsymbol{\varphi}$ \\
\hline 1300 & 130 & 1.6 \\
1300 & 120 & 1.49 \\
1300 & 110 & 1.36 \\
1300 & 100 & 1.24 \\
1300 & 90 & 1.11 \\
1300 & 80 & 0.99 \\
\hline
\end{tabular}

Table 2. Heeling angle when changing the position of load.

\begin{tabular}{lll}
\hline $\mathbf{m}$ & $\mathbf{d}$ & $\boldsymbol{\varphi}$ \\
\hline 1300 & 42 & 6.73 \\
1300 & 35 & 5.61 \\
1300 & 28 & 4.48 \\
1300 & 21 & 3.36 \\
1300 & 14 & 2.24 \\
1300 & 7 & 1.12 \\
\hline
\end{tabular}

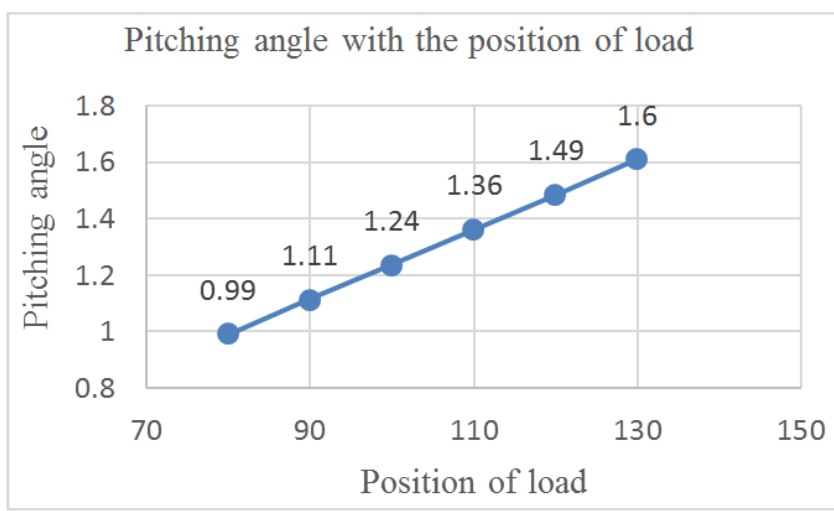

Figure 7. Diagram of Pitching angle when changing the position of load.

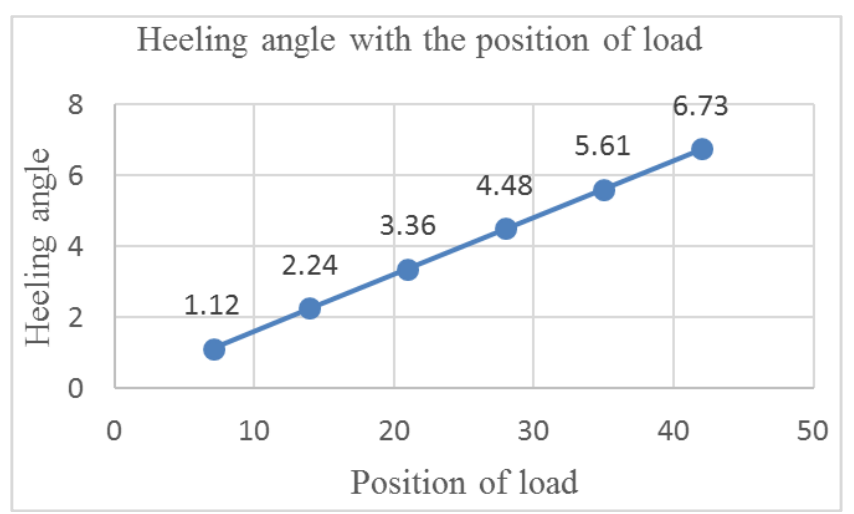

Figure 8. Diagram of Heeling angle when changing the position of load.

\subsection{Result in Modelling Software}

In order to describe the result clearly, we would like to show some data in software modelling (figure 9).

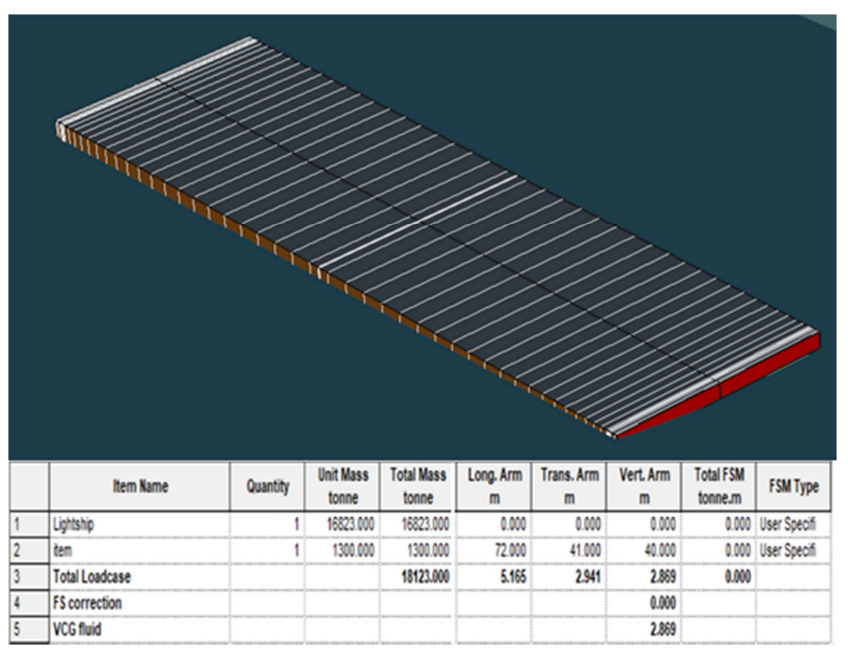

Figure 9. Full load and incline angle with Load case table.

We use full load as the load case for calculating when the crane reach maximum distance. Pitching and heeling angle are shown in figures 10 and 11 . We can see that the pitching angle is bigger than the heeling angle. In the next paper, we want to study about the pitching vibration of floating crane [11].

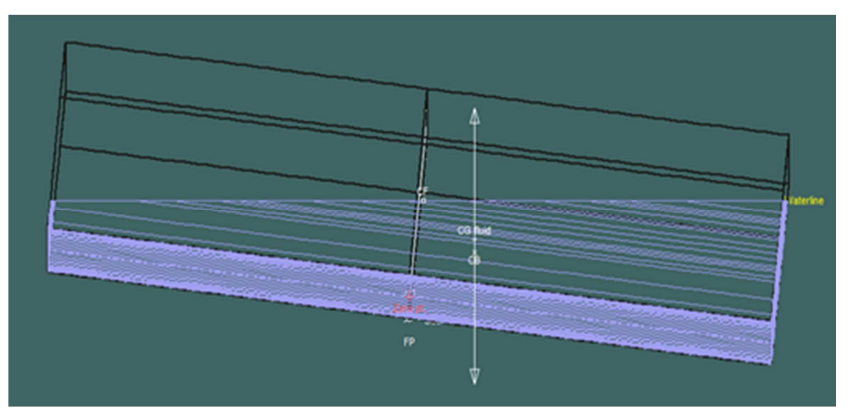

Figure 10. Pitching angle of floating crane.

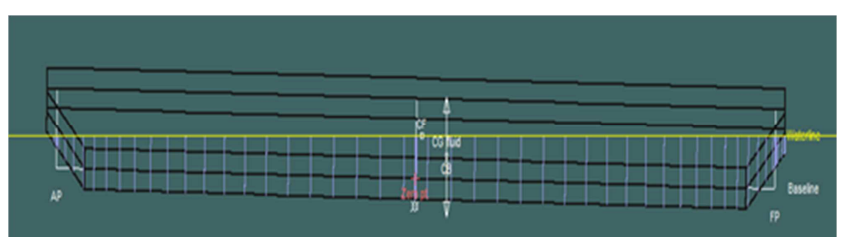

Figure 11. Heeling angle of floating crane.

\section{Summary}

In short, study of hydrotatic and stability of floating crane is the same boat or ship. However, floating crane often lifting heavy load in large distance that makes floating incline.

The result of this paper have showed the changing of heeling and pitching angle with full load condition.

The result can be used to analysis the stability of floating crane in wave condition or windy condition. Beside that's, we also want to use this result for studying the dynamic of floating crane in the future $[12,13]$.

In the next stage of dynamic study we will assume the load is hangging [14] and find out the vibration of floating crane in 
wave [15].

\section{References}

[1] Xiao-Rong Yang, Qiu-Ming Gan, Yan-Hong Wang and Guang-Dong Wang, "Dynamic response analysis of the lifting load system of a crane ship in irregular waves," Journal of Marine Science and Technology, Vol. 27, No. 6, 2019, pp. 481-497.

[2] V N Savinov. Calculated characteristics of the load-lifting device of nonself-propelled floating crane. Journal of Physics: Conf. Series 1177, 2019. 012044. <doi: $10.1088 / 1742-6596 / 1177 / 1 / 012044>$.

[3] Wilson, Philip A. Basic Naval ArchitectureShip Stability. Springer, 2018.

[4] Tran Cong Nghi. Ship theory. VNU-HCM press. Vietnam, 2016.

[5] Bryan Barrass Capt D R Derrett. Ship Stability for Masters and Mates. (7th Edition). Elsevier, 2012.

[6] Barge Stability Guidelines https://www.maritimenz.govt.nz/.

[7] Hoang Sa Floating Crane <https://www.marinetraffic.com/>.

[8] D G Musca (Anghelache). Static and dynamic stability for floating cranes. Materials Science and Eng. 400. 082015, 2018.

[9] Xiao-Rong Yang, Qiu-Ming Gan,Yan-Hong Wang, and Yong-Bo Zhou. Dynamic reliability analysis of the crane ship lifting load system. Journal of Marine Science and Technology, Vol. 25, No. 5, 2017, pp. 552-562.

[10] Tomasz Haniszewski. Modeling the dynamics of cargo lifting process by overhead crane for dynamic overload factor estimation. < doi: 10.21595/jve.2016.17310>.

[11] Katrin Ellermann and Edwin J. Kreuzer. Nonlinear Dynamics in the Motion of Floating Cranes. Multibody System Dynamics, May 2003, <doi: 10.1023/A:1023361314261>.
[12] Yougang Sun, Wanli Li, Dashan Dong, Xiao Mei, Haiyan Qiang. Dynamics analysis and active control of a floating crane. Analiza dinamike i aktivno upravljanje ploveće dizalice, 2015.

[13] Tong Minhui; Wang Yuemin; Qiu Huiqing, Research on Dynamic Heave Compensation on Large Floating Crane in Deep Sea. Fifth International Conference on Measuring Technology and Mechatronics Automation, 2013.

[14] Ju-Hwan Cha, Myung-Il Roh, Kyu-Yeul Lee. Dynamic response simulation of a heavy cargo suspended by a floating crane based on multibody system dynamics. Ocean Engineering, Vol. 37, Iss 14-15, October 2010. Elsevier.

[15] Oskar Flink, Tommy Holmberg. Structural and Hydrostatic Analysis of Deployment Vessel. Uppsala University, 2015.

\section{Biography}

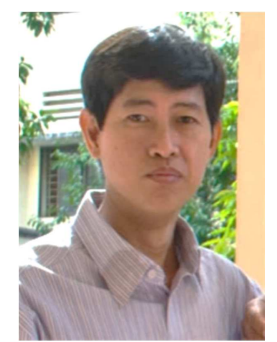

Tran Van Tao (born in 1976, HCM city). Lecturer, Facutly of Transportation Engineering, Ho Chi Minh city University of Technology (HCMUT), Ho Chi Minh city, Viet Nam. Since graduated Master of Engineering in Mechanical Engineering at HCMUT (2005) Mr. Tao has released about 20 scientific papers. He is also co-author of two books - instructions on ship construction and using computer in ship design.

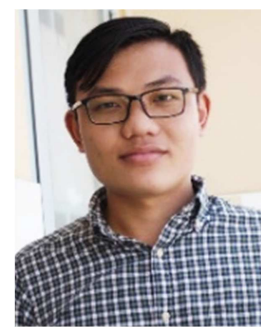

Nguyen Chien Luy. (born in 1998, Tien Giang Province, Viet Nam). He is a student, major in Naval Architecture at the University of Technology, Viet Nam National University - Ho Chi Minh city, Viet Nam. 